\title{
Karyotypic Variation in the Bryozoan Paludicella articulata
}

\author{
B. T. Backus
}

Department of Biology, The American University, Washington, D. C. 20016, U. S. A.

Received September 25, 1979

There have been few bryozoan chromosome studies. Moyano and Cea (1977) presented a $2 \mathrm{n}=12$ karyotype for Membranipora hyadesi. Potter (1979) and Backus 1977, 1979) karyotyped a few phylactolaemate species, and obtained data on some gymnolaemates. The $2 \mathrm{n}$ of the freshwater gymnolaemate Paludicella articulata was reported (Backus 1977, 1979) to be about 20, with (1979) the largest set having a submetacentric arm ratio of about $1: 2$. This paper reports a $2 n=22$ karyotype and, in at least some specimens, chromosomal heteromorphism and/or hyperploid cell lines.

\section{Materials and methods}

Colonies were collected at three sites in and near the Chesapeake and Ohio Canal within $20 \mathrm{Km}$ of Washington, D. C. . The first is where flow from a large pipe enters the Canal just below Lock 5 ; the second is the bypass channel at Lock 8 ; and the third is a stream from the Canal to the Potomac River at Great Falls, Maryland. Collections were made between April and July 1979. Preference was for tangled mats of zooecial strands, with growing ends not directly attached to substrate.

Colony ends (usually 1 or 2 developing zooids and terminal bud) were immersed in $0.05 \% \mathrm{w} / \mathrm{v}$ colchicine in tapwater for 55-75 minutes (longer exposure led to excessive chromosomal condensation). Lateral buds were occasionally used, but there was often contamination from other organisms attached to the parent zooid. Immediately after immersion, a thin thread was pulled from the zooecium, starting at the oldest part and going up as far as possible without disrupting developing polypides; if these were damaged, no spreads were obtained. Attempts to obtain good spreads by simply placing colony ends in $0.05 \%$ colchicine for $4-5$ hours were unsuccessful, although there were indications of metaphase arrest.

Material was fixed in $32 \%$ acetic acid-32\% methanol-36\% ethanol for at least 20 minutes. A colony end was touched to lens tissue to draw off fixative, placed in 2 drops of $60^{\circ} \mathrm{C} 60 \%$ acetic acid on a microscope slide, polypides and tip tissue were excised, and the zooecium was discarded. The suspension was allowed to stand 2-3 minutes, with occasional gentle rocking. The slide was rewarmed to $60^{\circ} \mathrm{C}$, and the coalescing acetic acid droplet was aspirated by hematocrit pipette. After drying, the slide was placed in $50 \%$ acetic acid for 10 seconds, washed under flowing tapwater, rinsed in distilled water, and stained 5-10 minutes in $\mathrm{pH} 7.0$ $0.1 \mathrm{M}$ phosphate-buffered giemsa. 


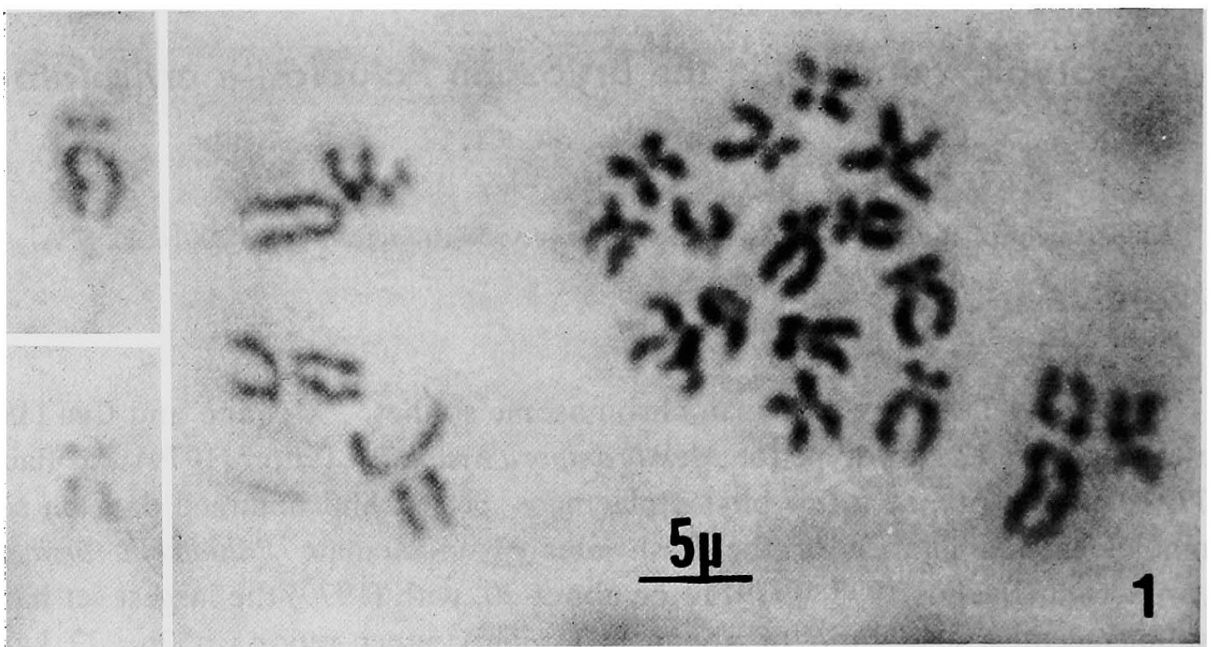

12

(1)

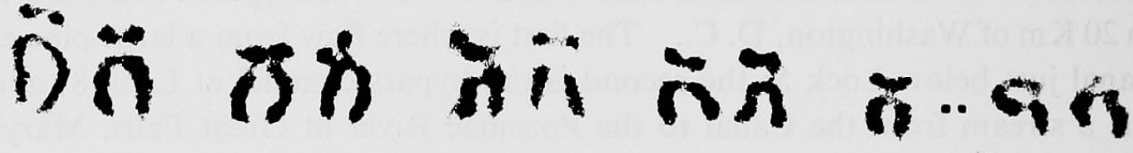

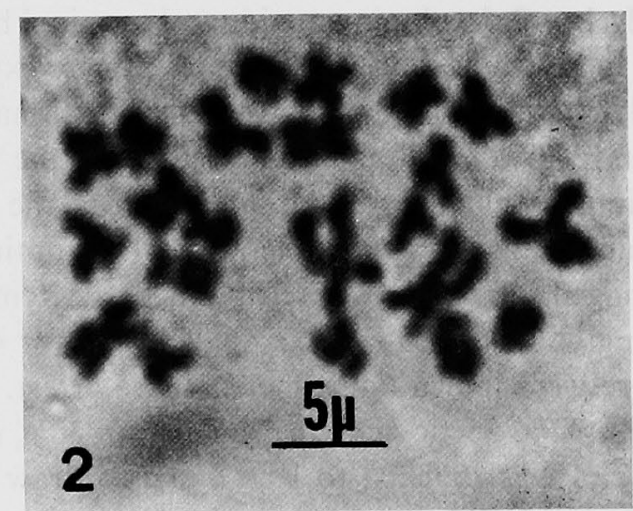

xx x $8 x \times x$

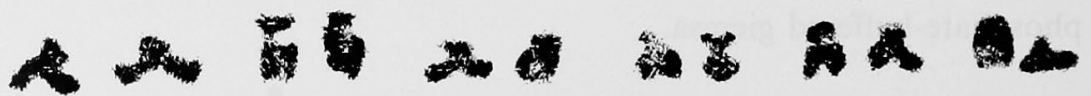




\section{Results}

About 60 well separated spreads were obtained. In many cases there was only one to a slide. Most obviously complete spreads (Figs. 2, 3) had $2 n=22$. The best morphology obtained is shown in Figure 1, although one of the smaller chromosomes is missing.

The usual karyotype (Figs. 1, 2) consists of one relatively large submetacentric (arm ratio 1:1.8), 4 metacentrics, and 6 subtelocentrics. It is particularly difficult to distinguish between the small metacentric 4th and 5th sets, and, among the subtelocentrics, between 6 and 7 and between 8 and 9 .

A few colonies from the second site gave consistent spreads (Fig. 3) in which a subtelocentric replaces a single member of one of the larger metacentric pairs (most probably from set 2). There may also be a slight variation in the short arms of one member of chromosome set 11.

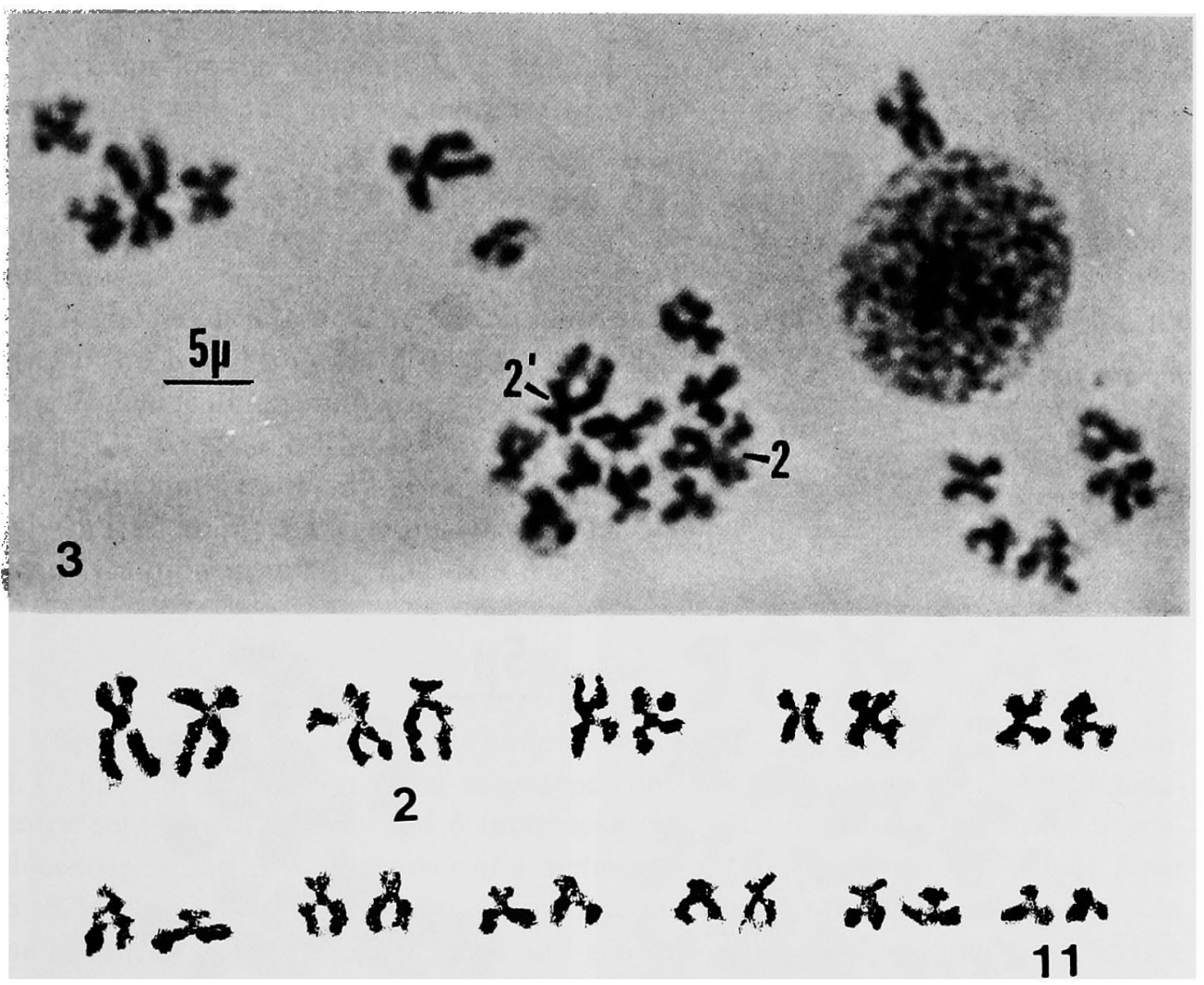

Fig. 3. Spread showing replacement of one of the members of a metacentric pair by a subtelocentric. Although this subtelocentric is shown paired with a normal metacentric 2 on the basis of size, it is possible it actually replaces one member of the 3rd set. The short arms of one of the members of set 11 appear larger than usual, suggesting heteromorphism here as well.

Figs. 1-2. 1, best chromosome morphology obtained for $P$. articulata and karyotype. One of the smaller chromosomes is missing. 2, a complete spread from $P$. articulata, with the usual karyo- 


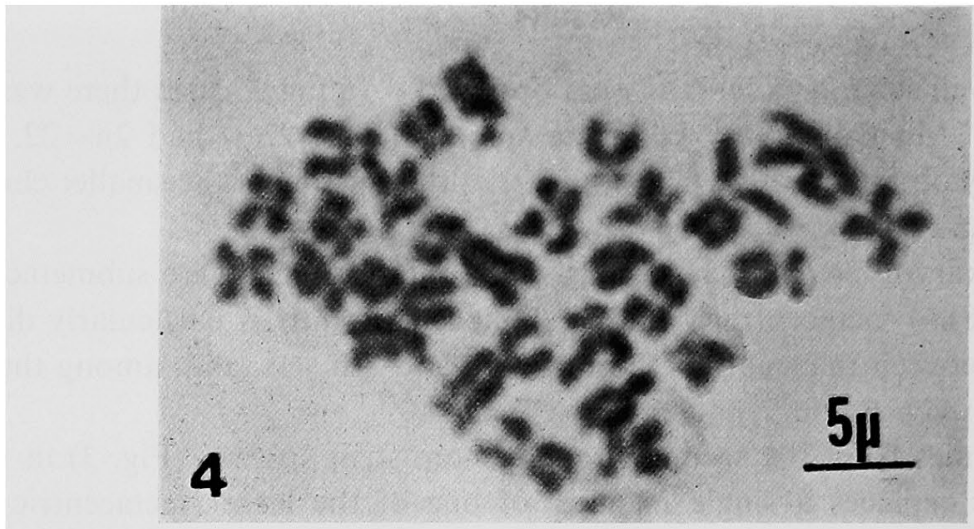

\section{ได้ 3}

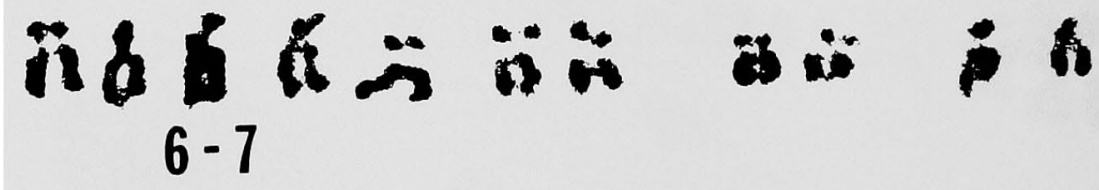
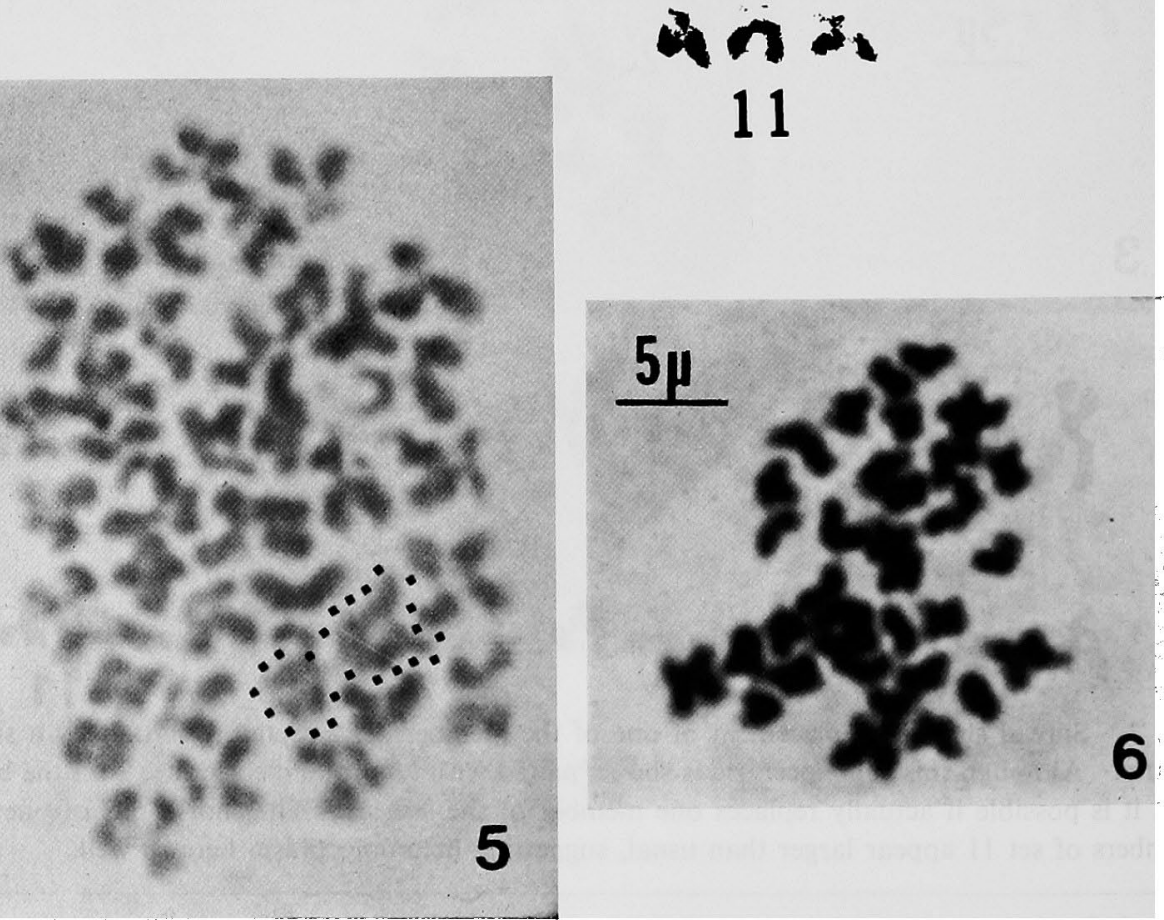
Several specimens collected in late May from the first site gave spreads with more than 22 chromosomes. One yielded a spread (Fig. 4) with 26 chromosomes; the karyotype suggests trisomy in sets $3,5,6$ or 7, and 10 or 11 . The same specimen also gave a spread with about 35 chromosomes (Fig. 5), originally thought to be contamination. However, arm ratios and relative sizes indicate these are $P$. articulata chromosomes, although only one member of the first set appears to be present. A specimen collected from the second site in July and exposed to colchicine for 100 minutes yielded 12 spreads with about 30-35 chromosomes (Fig. 6) and two with 22. This mitotically active material was from the growing tip, rather than developing polypides. This was one of the few specimens in which a thread had been pulled out to almost the end, but some others in which this occurred yielded only spreads with 22 chromosomes. Colonies yielding hyperploid spreads were morphologically normal.

\section{Discussion}

Except for the relatively large submetacentric, the $P$. articulata chromosomes seen in this study fall into two morphological groups, metacentric and subtelocentric. The heteromorphism found in some material appears to involve replacement of a single metacentric with a subtelocentric. There are no reports suggesting $P$. articulata is anything but hermaphroditic, so this is probably not a sex-determining mechanism.

It is difficult to speculate on the function of hyperploid cells in this species, the mechanism by which they arise, or even whether they are present in all colonies. $P$. articulata is unique in being a widely distributed freshwater gymnolaemate (Bushnell 1973), so these cells may have some adaptive significance. Cea and Moyano (1977) did not report any evidence of hyperploidy in Membranipora hyadesi, the only other karyotyped gymnolaemate. These hyperploid cells in P. articulata do suggest caution in interpreting data from other species in this phylum.

\section{Summary}

Specimens of Paludicella articulata collected in the vicinity of Washington, D. C. had $2 n=22$, with a usual karyotype consisting of a relatively large submetacentric set, 4 metacentrics, and 6 subtelocentrics. A few specimens showed a subtelocentric replacing one member of a metacentric set. Hyperploid cells, with from 26 to 35 chromosomes, were found in some morphologically normal colonies. In one instance, 12 hyperploid spreads and a few normal ones were obtained from a terminal bud. This is the first report of hyperploidy in the Bryozoa.

Figs. 4-6. 4, hyperploid spread with 26 chromosomes. The karyotype indicates trisomy in 4 sets. 5, hyperploid spread with about 35 chromosomes, obtained from the same specimen yielding the spread in Fig. 4. Only one member (outlined) of set 1 appears to be present. 6, hyperploid spread with 30-35 chromosomes, from terminal bud tissue. The excessive chromosomal condensation is due to exposure to colchicine for 100 minutes. 


\section{Acknowledgements}

I thank Professor W. C. Banta, Department of Biology, the American University, for his helpful comments during the preparation of this manuscript, and for use of the laboratory facilities. I also thank Professor T. S. Wood, Department of Biological Sciences, Wright State University, Dayton, Ohio, for helpful discussion on Paludicella articulata.

\section{References}

Backus, B. T. 1977. Some bryozoan karyotypes and chromosome numbers. Genet. Res. 29: $187-191$.

- 1979. Bryozoan chromosomes: Some evolutionary implications. In: Advances in Bryozoology (ed. G. P. Larwood). Academic Press, London, pp. 1-9.

Bushnell, J. H. 1973. The freshwater ectoprocta: A zoogeographical discussion. In: Living and Fossil Bryozoa: Recent Advances in Research (ed. G. P. Larwood). Academic Press, London. pp. 503-521.

Cea, G. F. and Moyano, H. I. 1977. Cromosomas de Bryozoa I. Los cromosomas de Membranipora hyadesi Jullien, 1888 . Cah. de Biol. Mar. 18: 133-139.

Potter, R. 1979. Bryozoan karyotypes and genome sizes. In: Advances in Bryozoology (ed. G. P. Larwood). Academic Press, London. pp. 11-32. 